\title{
Sobre ser enfermero y el futuro de la Enfermería
}

He reflexionado mucho en los últimos años sobre el significado de ser una enfermera y la práctica de enfermería y parece claro para mí que la mirada de la enfermera es el profesional de la salud y no de la enfermedad. Esto significa que miro para la persona, familia y comunidad que será objeto del cuidado y observo a este individuo/familia/comunidad como un todo psicosocioculturales-espirituales, más allá de lo biológico.Yo intento entender este individuo, sus aspiraciones, cómo se adapta o no a las condiciones internas y de su entorno y cómo puedo ser un facilitador en esas dimensiones para que esa adaptación logre el mejor potencial para su salud y autocuidado. Sin embargo, aún veo personas que llevan el título de licenciadas en enfermería y llevan en su mirada al profesional de la enfermedad, lo cual limita al ser/familia/comunidad que está observando a una queja o a un órgano específico, que consideran las dimensiones psicossócioculturales-espirituales irrelevantes y parte absolutamente secundario a ser tratada. Esta manera de pensar -créanme- es diametralmente opuesta a la dirección de la filosofía de la enfermería desde sus inicios y que garantiza que esta profesión es esencial para el futuro de la humanidad.

La NANDA (North American Nursing Diagnosis Association) 2012-2014 describe trece (13) Áreas de especialización de las enfermeras en su hacer. De estos 13, once (11) incluyen la esfera relacionada con la salud mental y psicosocio-espiritual de la persona, familia y comunidad, mientras que sólo dos (2) son de la esfera biológica. Entonces me pregunto: ¿Por qué es que todavía hay enfermeras que insisten en que los aspectos psicosocio-espirituales y culturales son "leves", "menos importantes", "complementarios", etc.?

Parece claro que la NANDA apunta que no. Es mejor terminar de entenderlo! Para la esfera biológica se ajusta el modelo biomédico (que es excelente para la Medicina). En todo caso, no hay necesidad de celebros pensantes en enfermería si sólo se considera la esfera biológica. El personal operativo (técnico y auxiliar de enfermería) son suficientes para proporcionar cuidados generales en esa esfera y hará de forma exacta y competente. ¿Sin embargo, cuántas heridas no se cierran o se infectan a pesar de los productos fantásticos que existen en el mercado fármaco-biomédico? Y ¿por qué? La mayoría de las veces porque la herida no es el foco central. Detrás de ella hay un ser humano que puede estar sufriendo emocionalmente, socialmente y espiritualmente y su incredulidad, frustración y aislamiento social provocan pérdida o disminución de la resistencia inmunológica a daños físicos.

Por más bueno que sea el tratamiento, sin la inyección de fe y esperanza o, a veces, solo escuchar, no se encontrarán los verdaderos y mejores caminos para la recuperación de esa persona. No es por nada que se ofrece una preparación intensiva para el curso de enfermería en pregrado con las disciplinas de comunicación, psicología, bioética y antropología. Estas son las herramientas esenciales para alcanzar el centro de curación al ser humano, que es su alma. Esta competencia es propia de la enfermera y no de su personal operativo. No habrá lugar en el futuro, para las enfermeras limitadas y sujetos al modelo biomédico.

Como enfermera y profesional liberal, quiero ser libre para conocer muy bien a mi clientela, pensar, diagnosticar sus necesidades, predecir los resultados de mi hacer y mi equipo, actuar o intervenir y evaluar el proceso y cómo el individuo responde; tanto interna como externamente a mi performance/intervención en la meta de mejorar su calidad de vida global, integrada y no dividida. Este individuo precisa volver a la sociedad confiado, con potencial de autocuidado motivado y participado de su proceso de salud. 
Tal vez me estoy volviendo vieja, no sé!. Después de todo, son treinta y tantos años de profesión (...) y los ancianos usualmente se vuelvan intolerantes y gruñen con reduccionismos y falta de visión de las personas, al menos en mi caso. Es importante ampliar la cosmovisión, predecir las futuras necesidades y resolver los problemas, en vez de estar lamentándonos. El personal de enfermería del futuro queda así: rico, con buena autoestima (¡basta de baja autoestima crónica $;$ ), muy, pero, MUY bien preparado y/o dispuesto a trabajar con los seres humanos en todas sus dimensiones, en consonancia con su linda y orgullosa historia! Lea más sobre Wanda Horta, Martha Rogers, Jean Watson, Florence Nightingale, entre otros. Estas personas no conformaron un montón de locas que se quedaban cavilando acerca de una enfermería perfecta, más sí sobre la importancia directa de la acción de Enfermería y de la enfermera en la prevención, la promoción de la salud y la recuperación de la persona como un todo y no solo en la esfera biológica. ¿Escogiste enfermería? Sea una Enfermera. ¿No estás contento? ¡Busca otra trabajo y sé feliz! El universo estará agradecido!

Ana Cristina de Sá

I Universidad Anhembi-Morumbi Laureate International - São Paulo - Brasil. 